hospitals were attributed to publicity about overuse. ${ }^{4}$ In our hospital use of chest radiography has fallen by $55 \%$ since the first survey. That appropriate use has been sustained or improved is suggested by a small increase in the proportion of patients admitted with an abnormal chest $x$ ray film. The increased proportion of examinations showing significant abnormality from $9 \%$ to $24 \%$ suggests a reduction in routine or screening radiography. The findings suggest that in adult psychiatry chest radiography should be used when there is clinical evidence of cardiothoracic disease or unexplained failure of an episode of mental illness to remit, and screening should be confined to alcoholism. ${ }^{1}$

A reduction of $51 \%$ in the use of skull radiography occurred after guidelines were issued to junior staff assessing head injuries. ${ }^{5}$ In our hospital the use of skull radiography has fallen by $42 \%$ since the first survey. All patients with an abnormality on computed tomography showed normal results on skull radiography. Skull radiography is thus not useful in adult psychiatry.

The use of computed tomography increased from $0.8 \%$ to $3 \cdot 3 \%$ of admissions. The proportion of abnormal results increased from $31 \%$ to $36 \%$, suggesting that clinical judgment is improving. Abnormal radiological findings were confined to patients with clinical evidence of organic brain disease. Prolonged or atypical affective psychoses accounted for most normal scans. The findings suggest that in adult psychiatry computed tomography is of value only when there are symptoms or signs of neurological disease.

1 Hughes J, Barraclough BM. Value of routine chest radiography of psychiatric patients. Br Med $\mathcal{f}$ 1980;281:1461-2.

2 Rastogi SC, Barraclough BM. Skull radiology in patients with psychiatric illness. $\mathrm{Br}$ Med $\mathcal{J}$ 1983;287:1259.

3 Roberts JKA, Lishman WA. The use of the CT scanner in psychiatry. Br $\mathcal{J}$ Psychiatry 1984; 145:152-8.

4 Roberts CJ, Fowkes FGR, Ennis WP, Mitchell M. Possible impact of audit on chest $x$-ray requests from surgical wards. Lancet 1983;ii:446-8.

5 Fowkes FGR, Evans RC, Williams LA, Gehlbach SH, Cooke BRB, Roberts CJ. Implementation of guidelines for skull $\mathrm{x}$-ray in patients with head injuries. Lancet 1984;ii: 795-7.

(Accepted 9 Fanuary 1986)

Department of Psychiatry, Royal South Hants Hospital, Southampton SO9 4PE

ANTHONY J WHITE, MRCPSYCH, registrar in psychiatry

BRIAN BARRACLOUGH, FRACP, senior lecturer in psychiatry

Correspondence to: Dr A J White, Barrow Hospital, Bristol BS19 3SG.

\title{
Low serum C4 concentrations and microangiopathy in type I and type II diabetes
}

Low $\mathrm{C} 4$ concentrations are thought to occur in about $25 \%$ of type I diabetics and are probably related to an increased frequency of the null alleles for $\mathrm{C} 4 .^{12}$ A recent study suggested that low $\mathrm{C} 4$ concentrations reflect and may predict microvascular disease in type I diabetics. ${ }^{3}$ We studied the relation of serum C4 concentrations to microvascular complications in 123 type I and 140 type II diabetics.

\section{Patients, methods, and results}

We studied all 263 patients who attended the Austin Hospital diabetes clinic between November 1984 and April 1985. The patients were regarded as having type I diabetes if they had persistent ketonuria, weight loss on presentation, and insulin dependency within one month of diagnosis $(n=123)$; all other patients were classified as having type II diabetes $(n=140)$. Serum $C 4$ concentrations were measured by radial immunodiffusion (Kallestad). ${ }^{4}$ Proliferative retinopathy was diagnosed independently by an ophthalmologist. Diabetic nephropathy was defined as proteinuria exceeding $0.3 \mathrm{~g} / 24 \mathrm{~h}$ by a trichloroacetic acid precipitation method (all dipstick results (Albustix) $\geqslant 0.3 \mathrm{~g} / \mathrm{l}$ ). ${ }^{5}$ Statistical comparisons were performed using Student's $t$ test for normally distributed variables, the MannWhitney (W) test for $\mathrm{C} 4$ concentrations, and $\chi^{2}$ analysis for comparing the prevalence of retinopathy and proteinuria on dipstick testing between different groups.

Fourteen type I and 11 type II diabetics had proliferative retinopathy, and 19 and 24 , respectively, had proteinuria on dipstick testing; creatinine clearance was $1.74(0.06) \mathrm{ml} / \mathrm{s}$ in type I and $1.61(0.06) \mathrm{ml} / \mathrm{s}$ in type II diabetics. Type I diabetics had lower $\mathrm{C} 4$ concentrations than type II diabetics (median $20 v 27.5 \mathrm{mg} / 100 \mathrm{ml}$ Mann-Whitney test $p<0.001$ ). There was no significant difference in $C 4$ concentrations between patients with and without microvascular complications in type I or type II diabetics (table). There was no correlation between $\mathrm{C} 4$ concentrations and duration of diabetes, the age of the patient at the time of study, and the age of the patient at diagnosis.

Mean (SEM) serum C4 concentrations in diabetics with and without microvascular complications $(\mathrm{mg} / 100 \mathrm{ml})^{\star}$

\begin{tabular}{lcclccc}
\hline & \multicolumn{2}{c}{ Type I diabetics } & & \multicolumn{2}{c}{ Type II diabetics } \\
\cline { 2 - 3 } \cline { 5 - 6 } \cline { 5 - 6 } & No of patients & $\mathrm{C} 4$ & & No of patients & $\mathrm{C} 4$ \\
\hline Total group & 123 & $22 \cdot 0(0 \cdot 8)$ & & 140 & $28 \cdot 3(0 \cdot 8)$ \\
Yroliferative retinopathy & 21 & $25 \cdot 9(2 \cdot 8)$ & & 11 & $30 \cdot 1(4 \cdot 6)$ \\
Diabetic nephropathy & 21 & $23 \cdot 0(2 \cdot 1)$ & & 32 & $28 \cdot 9(2 \cdot 0)$ \\
$\begin{array}{l}\text { No microvascular } \\
\text { complications }\end{array}$ & 97 & $21 \cdot 2(0 \cdot 8)$ & & 102 & $28 \cdot 2(0 \cdot 9)$ \\
\hline
\end{tabular}

*Normal range based on 50 normal subjects is $16-45 \mathrm{mg} / 100 \mathrm{ml}$ (means $2 \mathrm{SD}$ ). Type I $v$ type II: $\mathrm{p}<0.001$.
The prevalence of microvascular complications in type I diabetics with $\mathrm{C} 4$ concentrations below the normal range $(<16 \mathrm{mg} / 100 \mathrm{ml})$ was compared with that in type I diabetics with $\mathrm{C} 4$ concentrations within the normal range. There was no difference in the prevalence of retinopathy (numbers of patients with nil, background, proliferative retinopathy $19,5,3, v 71,14,11 ; \chi^{2}=0 \cdot 21$, NS), creatinine clearance $(1.74(0.11) v 1.74(0.07) \mathrm{ml} / \mathrm{s} ; \mathrm{p}=0.99)$, or proteinuria on dipstick testing $\left(6 / 27 v 14 / 95 ; \chi^{2}=0 \cdot 86\right.$, NS) between type I diabetics with low $(n=27)$ and normal $C 4$ concentrations $(n=96)$.

\section{Comment}

These results confirm previous reports that about a quarter of type I diabetics have subnormal C4 concentrations. ${ }^{1}$ This was not found in type II diabetics. Type I diabetics with advanced microvascular disease did not show further lowering of $\mathrm{C} 4$ concentrations compared with diabetics without complications. These data are in contrast with findings of a previous study in which type I diabetics with complications had lower $\mathrm{C} 4$ concentrations than type I diabetics without complications. ${ }^{3}$ The difference in results between the two studies is difficult to explain in terms of patient selection, criteria for type I and type II diabetes, definition of microvascular complications, and assay methods. This study suggests that low serum C4 concentrations are a manifestation of type I diabetes, independent of the presence of microvascular disease.

1 Vergani D, Johnston C, Abdullah NB, Barnett AH. Low serum C4 concentrations: an inherited predisposition to insulin dependent diabetes. BrMed f 1983;286:926-8.

O'Neill GJ, Young SY, Dupont B. Two HLA linked loci controlling the 4 th component of human complement. Proc Natl Acad Sci USA 1978;75:5165-9.

3 Barnett AH, Mijovic C, Fletcher J, et al. Low plasma C4 concentrations: association with microangiopathy in insulin dependent diabetes. Br Med f 1984;289:943-5.

4 Mancini G, Carbonara AO, Heremans SF. Immunochemical quantitation of antigens by single radial immunodiffusion. Immunochemistry 1965;2:235-54.

5 Koller A. Total urine protein. In: Kaplan L, Pesce A, eds. Clinical chemistry. Missouri: C V Mosby and Co, 1984:1319-24.

(Accepted 6 fanuary 1986)

Endocrine Units and Departments of Medicine and Immunohaematology,

University of Melbourne, Austin Hospital, Victoria 3084, Australia

MARK E COOPER, MB, BS, endocrine fellow

RICHARD DUFF, MB, BS, resident medical officer

RUSSELL BUCHANAN, MB, FRACP, lecturer in medicine

JEFF MCPHERSON, MSC, senior scientist

GEORGE JERUMS, MD, FRACP, senior endocrinologist

Correspondence and requests for reprints to: Dr Cooper. 